\title{
İnternet Tabanlı Epistemolojik İnançlar Ölçeği Türkçe Uyarlama Çalışması ve Öğretmen Adayları ile Bir İnceleme
}

\section{Turkish Adaptation of Internet Based Epistemological Beliefs Scale and An Investigation with Pre-Service Teachers}

\author{
Ridvan ATA*, Muhammet Mustafa ALPASLAN**
}

\begin{abstract}
Öz: Bu çalışmada ilk olarak Braten, Brandmo ve Kammerer (2018) tarafından geliştirilen ve 12 maddeden oluşan “İnternet Tabanlı Epistemolojik İnançlar Ölçeğinin” Türkçe'ye uyarlaması yapılmıştır. Ardından uyarlanan ölçek ile öğretmen adaylarının internet tabanlı epistemolojik inançları ile internet kullanımları çeşitli değişkenler göz önünde bulundurularak incelenmiştir. Ölçeğin orijinali 3 faktörlü bir yapıya sahiptir. Bu faktörler otoriteyle gerekçelendirme, birden fazla kaynak ile gerekçelendirme ve kişisel deneyimlerle gerekçelendirme olarak isimlendirilmiştir. Ölçeğin Türkçe'ye uyarlama çalışmaları dilsel eşdeğerlik ile başlamış, dilsel eşdeğerliğin ardından DFA ve güvenirlik analizleri gerçekleştirilmiştir. 375 öğretmen adaylarından elde edilen verilerin analiz sonuçları ölçeğin güvenilir ve geçerli olduğu göstermiştir. Ayrıca öğretmen adaylarının internet tabanlı epistemolojik inançlarının gelir düzeyi, anne eğitim seviyesi ve internet kullanım sıklığı ile pozitif ilişki olduğu görülmüştür. Bunlara ek olarak kentsel kesimde yaşayan, dizüstü bilgisayar kullanan ve interneti eğitim/bilimsel araştırma için kullanan öğretmen adaylarının internet tabanlı epistemolojik inançları diğerlerine göre daha yüksek olduğu görülmüştür.
\end{abstract}

Anahtar Kelimeler: Epistemolojik inançlar, internet kullanımı, öğretmen eğitimi, ölçek uyarlama

\begin{abstract}
In this study, first "Internet-based Epistemological Belief Scale", which was developed by Braten, Brandmo and Kammerer (2018) and consists of 12 items, was adapted to Turkish. Then, internetbased epistemological beliefs and internet usage of pre-service teachers were examined by this adapted scale considering various variables. The original scale has a 3 -factor structure, which are justification by authority, justification by multiple sources, and personal justification. Turkish adaptation of the scale was started with linguistic equivalence and then confirmatory factor analysis and reliability analyzes were carried out. The results of the data obtained from 375 pre-service teachers indicate that the scale is reliable and valid. In addition, it was observed that there is a positive relationship between pre-service teachers' internet-based epistemological beliefs, family income level, mother education level and frequency of internet usage. Furthermore, internet-based epistemological belief levels of the pre-service teacher's upbringing in urban areas, using laptops and using internet for educational / scientific research were found to be higher than others. Findings were then discussed in lights of relevant literature.
\end{abstract}

Keywords: Epistemological beliefs; internet use; teacher education, scale adaptation

Giriş

Bilgi, internet çağında çok önemlidir. İnternet ortamı, bilgi aramada önemli bir rol oynamaktadır ve birçok farklı bilgi kaynağına kolay erişim sağlamaktadır. Bilgi her an mevcuttur ve her yerden erişilebilir. Bu nedenle internet, giderek bir bilgi kaynağı ve dünya ile daha fazla iletişim kurmada ana mecra haline gelmiştir. You, Lee, Lee ve Kang (2013) interneti kullanmada motive edici faktörlerin ilk olarak bilgi arama, bilgi takibi, eğlence ve sosyal fayda olduğunu belirtmiştir. Özellikle en yaygın üç çevrimiçi etkinliğin, bilgiyi bulmak için bir arama motoru kullanma, sosyal ağ siteleri (ör., Facebook ve Twitter) ve haber okuma olduğu yapılan araştırmalarda görülmektedir (Pew Research Center, 2010). Bu bulgular çevrimiçi ortamların

\footnotetext{
*Dr Öğr. Üyesi, Muğla Sıtkı Koçman Üniversitesi, Eğitim Fakültesi, Muğla-Türkiye, ORCID: 0000-0002-5008-9328 ,e-posta: ridvanata@mu.edu.tr

**Doç Dr, Muğla Sıtkı Koçman Üniversitesi, Eğitim Fakültesi, Muğla-Türkiye, ORCID: 0000-0003-4222-7468 ,eposta: mustafaalpaslan@mu.edu.tr
} 
kullanımlarıyla ilgili bireylerin asıl davranıșlarını anlamak ve öngörüde bulunmak için bir temel oluşturmaktadır (Go, You, Jung ve Shim, 2016).

Türkiye İstatistik Kurumu (TUİK, 2018) verilerine göre Türkiye'de internet kullanan bireylerin oranı \%72,9'a yükselmiştir. Yine hanehalkı bilişim teknolojileri kullanım araştırması sonuçlarına göre 2018 y1lında hanelerin \%83,8'si evden internet erişim imkânına sahip olmuştur. Diğer bir ifadeyle her on hanenin sekizi internet erişim imkânına sahiptir. Ancak, bilgi paylaşımı ve yayını internette ücretsiz ve özgürce gerçekleştirildiğinden çevrimiçi bilgiler, kalite ve doğruluk bakımından önemli ölçüde farklılık gösterebilmektedir. İnternet ortamı farklı bölgelerde ve çoğunlukla birbirini tanımayan bireyler arasında bilgi paylaşımına izin verir ve karakteristik olarak bir kaynağın veya bilginin güvenirliğini belirleme konusunda bireylere yardımcı olan ipuçları, çevrimiçi ortamlarda genellikle belirsizdir veya çoğu zaman yoktur (Hajli, 2018; Westerman, Spence ve Van Der Heide, 2014). Bu yüzden, internette yayınlanan bilgiler her zaman güvenilir değildir. Çoğu zaman gözden geçirilmemiş ve herkese açıktır. Çevrimiçi ortamlarda genellikle dikkat çekmek için yanlış, gözden geçirilmemiş ve yönlendirilmiş bilgiler sunulabilmektedir. Aynı zamanda, internet ortamında yanlış bilgilerle yönlendirmek için yapılan sistematik girişimler artarak eğilim haline gelmektedir. Güvenilip bu yanlış bilgilere göre harekete geçilirse birçok durumda olumsuz sonuçlar ortaya çıkabilir. $\mathrm{Bu}$ nedenle, çevrimiçi karşılaşılan bilgilerin internet kullanıcıları tarafından eleştirel olarak değerlendirilmesi gerekmektedir. Benzer şekilde bilgiyi arayanların, kullanıcı tarafindan oluşturulan ve belirlenen içeriğe giderek daha fazla güvenmeleri ve bunu başkalarıyla paylaşımlarından dolayı internet üzerinden eriştikleri bilgilerin güvenilirliğini nasıl değerlendirdiklerini anlamak daha önemli hale gelmiştir. Bununla birlikte, bilgi kaynağının doğruluğu ve algılanan güvenirliği belirli alanlarda (ör, sağlık, akademi) özellikle önemli olabilir.

Diğer taraftan, epistemolojik inanç bireyin bilginin ve bilmenin doğasıyla ilgili fikirlerini ifade etmektedir. Alan yazında yapılan çalışmalarda epistemolojik inançla ilgili farklı terimler- epistemolojik teoriler, epistemolojik inançlar, kişisel epistemoloji ve epistemik bilişkullanılmıştır (Hofer, 2016). Epistemolojik inançlar ile ilgili ilk çalışmalar Perry (1970) tarafından üniversite öğrencileri üzerine yapılmıştır. Perry (1970) üniversite öğrencileri nasıl bilirler, bilme hakkındaki fikirleri nelerdir ve düşünme ve mantıksal çıkarımların bilmede rolü nedir sorularına yanıt aramış ve epistemolojik inançlarla ilgili ilk modeli ortaya koymuştur. Perry'ye göre epistemolojik gelişim birbirini takip eden dokuz aşama ve dört başlıktan oluşmaktadır. İlk aşama olan ikicil (düalistik) aşamada birey bilgiyi doğru veya yanlış olarak tanımlarken, son aşama olan göreli kararlı olma aşamasında birey bilmenin ve bilginin kaynağı olarak kendisini görmektedir.

Perry’nin ilk çalışmadan sonra epistemolojik inançlar ile ilgili birçok farklı modeller ortaya atılmıştır. Bu modeller genellikle üç başlık altında toplanmaktadır (Hofer, 2016). Birinci grup modeller epistemolojik inançları gelişimsel bir bilişsel öğe olarak tanımlayan ve eğitim ve yaş ile beraber kişinin daha naif düzeyden daha üstün (sophisticated) düzeye doğru gelişim göstereceğini savunur. Daha çok nitel ve uzun gözlemler sonucu geliştirilen bu modelin bir örneği King ve Kitchener (2002) tarafından ortaya atılan yansıtıcı yargı modelidir. Bu model bireyin bilmenin süreci ve bu sürecin nasıl olduğu ile ilgilenir. King ve Kitchener (2002) modeli yedi aşamada ve üç ana dönemde oluşturulmuştur. İlk dönem olan ön-yansıtıcı muhakeme dönemde birey bilgiyi otoritenin sözleri ya da ilk el gözlemlerin sonucu olarak görür. İkinci dönem olan kısmı- yansıtıcı muhakeme döneminde birey bilginin kesin olmadığını düşünür; fakat delillerin bilimsel muhakemede rolünü açıklayamazlar. Son aşama olan yansıtıcı muhakeme döneminde ise birey bilgiyle ilgili söylemlerin kesin olmadığını fakat mevcut bilginin var olan bilimsel yöntem ve delillerle en iyi açıklamalar olduğunu düşünür.

İkinci grup modeller epistemolojik inançları çoklu-boyutta inceleyen modellerdir. Gelişimsel modellerde epistemolojik inançların yaş veya eğitim gibi faktörler gelişmektedir. Bu modeller epistemolojik inançlardaki gelişmenin hangi eğitimsel uygulamalar ile gelişebileceği konusunda eksik kalmaktadır. $\mathrm{Bu}$ nedenle epistemolojik inançları tek boyutta inceleyen gelişimsel modellere alternatif olarak epistemolojik inançları çoklu boyutlarda tanımlayan 
modeller ortaya çıkmıştır (Alpaslan ve Ulubey, 2016). İlk öncülerinden biri Schommer'dir (1990). Schommer epistemolojik inançları beş farklı alt-boyutta -bilginin kesinliği, bilginin yapısı, bilginin kaynağı, öğrenme yeteneği ve öğrenme hızı- nicel ölçme araçları kullanarak incelemiştir. Hofer ve Pintrich (1997) epistemolojik inançları bilmenin doğası ve bilginin doğası olmak üzere iki başlıkta incelemiştir. Bilmenin doğası bilginin kaynağı- bireyin bilgi kaynağı olarak kendisini ya da başka kişileri görmesi- ve bilginin gerekçelendirilmesi - bilginin gerekçelendirilmesinde delil ve teorilerin rolü- olmak üzere iki alt-başlıktan oluşmaktadır. Aynı şekilde bilginin doğası bilginin gelişimi-bilgilerin birbiriyle ilişkili olma durumu- ve bilginin kesinliği - bilginin kesin veya değişebilir olması- olmak üzere iki alt-başlıktan oluşmuştur.

Bazı bilim insanları epistemolojik inançların belirlenirken genel bir epistemolojik inanç ölçülmesinden ziyade epistemolojik inançların sosyal bağlama ve sahip olduğu deneyimler sonucu farklı olabileceğini ve bu nedenle daha küçük parçalar halinde (konu alanı yâda bağlamsal olarak) incelenmesinin daha doğru olacağını savunmuştur (Alpaslan, Yalvac ve Loving, 2017). Üçüncü gruptaki bu modellere göre, örneğin, bir matematikçinin bir matematik önermesi hakkındaki epistemolojik fikirleri o kişinin tarih alanındaki bir önerme için epistemolojik fikirleri aynı olmayacaktır. Dahası, Hammer ve Elby (2002) tarafindan ortaya konulan epistemolojik kaynaklar modelinde Hammer ve Elby, bilginin sosyo-bağlamsal bir ürün olduğu için, bireyin bilgiyle ilgili fikirlerinin sosyal bağlama göre değişebileceğini ve bu nedenle epistemolojik inançlar ile ilgili araştırmaların bireyin bağlamsal değişkenleri göz önüne alarak araştırması gerektiğini savunmaktadır.

Bu çalışmayı yönlendiren epistemolojik inanç teorisi Greene, Azevedo ve Tomey-Purta (2008) tarafindan geliştirilen epistemik biliş kuramıdır. Epistemik biliş (epistemic cognition) bireyin bilgi ve bilme ile ilgili kavramları gelişimini ve uygulanmasını içeren zihinsel süreç olarak tanımlanır. Epistemik biliş kuramı alanyazında yapılan çalışmaları, önceki kuramları ve epistemolojinin felsefik anlamı göz önüne alınarak oluşturulmuştur. Greene ve diğerleri epistemik biliş kuramını üç argüman üzerine inşa etmiştir. Birincisi terminoloji üzerinedir. Epistemolojik inançlar kişinin bilginin ve bilmenin doğası üzerine fikirlerini ifade ederken bu fikirlerin bir kullanımı ile ilgili bir süreci içermemektedir. Bu nedenle Greene ve diğerleri "epistemik biliş" kavramının bilginin ve bilmenin doğasıyla ilgili öğrenmede uygulamaya konulma sürecini daha doğru yansıttığı için kullanılması gerektiğini savunmaktadır. Yani duyuşsal bir özellik olarak değil bilişsel bir özellik olduğuna vurgu yapmışlardır. İkinci nokta, Hofer ve Pintrich (1997) epistemolojik inançlar kuramındaki bilginin doğasıyla ilgili altbaşlıklar felsefenin diğer alt dalı olan ontoloji kapsamına girmektedir ve epistemolojinin kapsamı dışındadır. Epistemoloji bilmenin yolları ile ilgilendiği için (how we know what we know) Hofer ve Pintrich tarafindan tanımlanan epistemolojik inanç alt boyutlarından sadece bilginin gerekçelendirilmesi epistemik biliş kapsamına girdiğini söylemektedir. Son olarak Greene ve diğerleri epistemik bilişin bağlamsal yapısını göz önüne alarak, birden farklı yollarla yapılabildiği için (ör., kişisel deneyim, otorite ile, delil ile gerekçelendirme vb.), bilginin gerekçelendirilmesinin çok boyutlu bir yapı olarak ele alınması gerektiğini savunmuşlardır.

Araştırmalar epistemik bilişin öğrencilerin motivasyonuna, biliş ve üstbiliş̧ stratejileri, kavramsal anlayışına ve karar verme süreciyle ilişkili olduğunu göstermektedir (Alpaslan, 2017; Alpaslan, Yalvac, ve Willson, 2017; Mason, Ariasi, ve Boldrin, 2011; Şenler ve İrven, 2017; Strømsø ve Bråten, 2010). Epistemik biliş öğrencilerin bilimsel iddiaları anlamasına ve yorumlanmasına etki etmektedir (Sinatra, Kienhues ve Hofer, 2014). Epistemik biliş öğrencilerin öğrenme için belirlediği standartları ve yeni öğrenme görevleri yorumlarını ve bunlarla ilgili yönelimlerini etkilemektedir (Muis, 2007). 282 üniversite öğrencisinin katıldığ çalışmada Trevors, Muis, Pekrun, Sinatra ve Muijseaar (2017) epistemik biliş, duygu ve yazılı materyalden öğrenme arasındaki ilişkiyi incelemiştir. Trevors ve diğerleri (2017) epistemik bilişin öğrencilerin akademik duyguları ve öğrenmeleri ile ilişkili olduğunu göstermiştir. Örneğin, öğrencilerin deneyler ve sorgulamayla bilgiyi gerekçelendirilmesine ilişki fikirleri, merak ve eğlenme gibi duygularla ve kavramsal öğrenme ile ilişkiliyken; otoriteye dayalı bilgiyi gerekçelendirme fikirleri ezbere dayalı öğrenme ile ilişkilidir. 


\section{Araştırmanın önemi ve amacı}

İnternet tabanlı öğrenme bağlamında öğrencilerin çevrimiçi öğrenmelerinde epistemik inançlarının önemi araştııılmış ve yapılan çalışmalar çevrimiçi bilgi arama esnasında kişisel epistemik inançların etkin olduğunu göstermiştir (Mason, Boldrin ve Ariasi, 2010). Özellikle öğrencilerin eğitim seviyesi arttıkça internet tabanlı bilginin belirsizliğine ilişkin epistemik inanışa sahip olma eğilimi gösterdikleri ve internetin doğru bilgiyi içeren iyi bir kaynak olduğu düşüncesine şüpheyle yaklaştıkları ve internet tabanlı bilgiyi diğer kaynaklarla doğrulama ve değerlendirme eğiliminde oldukları görülmüsstür (Chiu, Liang ve Tsai, 2016). Diğer bir çalışmada Greene, Yu ve Copeland (2014) öğrencilerin internet öğrenme ortamında öğrenmeleri, epistemik biliş ve öz-düzenleyici öğrenme arasındaki ilişkiyi incelemiştir. Ön- ve son-test analiz sonuçları, öğrencilerin epistemik bilişlerinin not alma ve açımlayıcı öğrenme stratejileri ile ilişkili olduğunu göstermiştir. Benzer şekilde, internette arama deneyimi fazla olan öğrencilerin internet tabanlı bilginin kesinliğini ve kaynağını daha fazla irdeledikleri, analitik ve üstbilișsel stratejiler geliștirdikleri görülmektedir (Cevik, 2015). Yine de internetin bilgi kaynağı olarak düşünüldüğünde sofistike epistemik inançların öğrenme üzerindeki olumlu etkilerinin ve kişisel epistemik inançların rolünün yeniden sorgulanmas1 gerektiği belirtilmektedir (Cheng, Liang ve Tsai, 2013). Yapılan araştırmanın bu yönüyle alanyazına katkı sağlayacağı düşünülmektedir. Bu araştırmada, aşağıdaki sorulara cevap aranmıştır;

1. Veri toplama aracı olarak kullanılan ve Türkçe'ye uyarlanan İnternet Tabanlı Epistemolojik İnançlar ölçeği geçerli ve güvenilir midir?

2. Öğretmen adaylarının internet tabanlı epistemolojik inanç düzeyleri nedir?

3. Öğretmen adaylarının internet kullanım düzeyleri nedir?

4. Öğretmen adaylarının internet tabanlı epistemolojik inanç düzeylerinde cinsiyet, bölüm anne ve baba eğitim düzeyi, büyüdüğü yerleşim yeri, aylık gelir düzeyi, internet kullanım sıklığı, kullanılan erişim aracı ve kullanım amacına göre farklılık var mıdır?

5. Öğretmen adaylarının internet tabanlı epistemolojik inanç düzeyleri anne ve baba eğitim düzeyi, gelir düzeyi ve internet kullanım sıklığı ile ilişkili midir?

\section{Yöntem}

$\mathrm{Bu}$ bölüm, araştırma modeli, araştırmaya katılan çalışma grubu, veri toplama araçlarının özellikleri, ölçek uyarlaması sırasında gerçekleştirilen süreçler ve diğer veri analizleri hakkında bilgi vermektedir.

\section{Araştırma modeli}

Çalışma iki aşamadan oluşmaktadır. Her iki aşamada betimsel ve ilişkisel araştırma modelinde oluşturulmuştur. İlk aşamada bir ölçek uyarlaması gerçekleştirilmiştir. İkinci aşama ise ilişkisel araştırma modelinde gerçekleştirilmiştir ve çeşitli değişkenler göz önünde bulundurularak öğretmen adaylarının internet tabanlı epistemolojik inançları ile internet kullanımları arasındaki ilişkiler incelenmiştir. Bu bağlamda doğrulayıcı faktör analizi, iç tutarlılık çalışmaları ve ilişkisel analiz teknikleri bu kişilerden elde edilen veriler üzerinden yapılmıştır.

\section{Örneklem/çalışma grubu}

İnternet Tabanlı Epistemolojik İnançlar Ölçeğinin geçerlik ve güvenirlik çalışmaları 2018-2019 öğretim yılı Bahar ve Güz dönemlerinde farklı üniversitelerin Eğitim fakültelerinin farklı bölümlerinde öğrenim gören öğrenciler ile yürütülmüştür. Örneklemin belirlenmesinde olasılığa dayalı olmayan örnekleme tekniklerinden uygun örnekleme tekniği kullanışmıştır. Ayrıca maksimum çeşitlilik sağlanması amacıyla farklı branşlarda eğitim gören öğretmen adayları çalışmaya davet edilmiştir. Araştırmanın örneklemini toplam 375 kişi oluşturmaktadır. Google Formlardan çevrimiçi ölçek oluşturulmuş ve araştırmacılar gönüllülük esasına dayanarak çalışmaya katılmışlardır. Katılımcıların 258 (68,8 \%) kadın ve 117 (31,2 \%) erkektir. Çalışma grubunun betimsel bilgileri aşağıdaki Tablo 1'de verilmiştir. 
Tablo 1.

Katılımcıların Demografik Özellikleri

\begin{tabular}{lll}
\hline Cinsiyet & N & Yüzde (\%) \\
\hline Kadın & 258 & 68,8 \\
Erkek & 117 & 31,2 \\
\hline Bölüm & & \\
\hline Fen bilgisi öğretmenliği & 24,3 \\
İlköğretim Matematik Öğretmenliği & 39 & 10,4 \\
İngilizce Öğretmenliği & 28 & 7,5 \\
Okul öncesi öğretmenliği & 67 & 17,9 \\
Rehberlik ve Psikolojik Danışmanlık & 59 & 15,7 \\
Sınıf Öğretmenliği & 30 & 8,0 \\
Sosyal bilgiler öğretmenliği & 31 & 8,3 \\
Türkçe Öğretmenliği & 30 & 8,0 \\
\hline Anne eğitim düzeyi & & \\
\hline İlköğretim & 132 & 35,2 \\
Ortaöğretim & 78 & 20,8 \\
Lise & 110 & 29,3 \\
Üniversite & 50 & 13,3 \\
Lisansüstü & 5 & 1,3 \\
\hline Baba eğitim düzeyi & & \\
\hline İlköğretim & 196 & 52,3 \\
Ortaöğretim & 75 & 20,0 \\
Lise & 74 & 19,7 \\
Üniversite & 28 & 7,5 \\
Lisansüstü & 2 \\
\hline Yetiştiği bölge & & \\
\hline Kırsal kesim & 106 & 28,3 \\
Kentsel kesim & 269 & 71,7 \\
\hline Ailenin aylık geliri & 151 & \\
\hline 0-2000 TL & 149 & 30,3 \\
2001-4000 TL & 75 & 20,0 \\
4001 TL- üstü & & \\
& & \\
\hline & & \\
\hline
\end{tabular}

\section{Veri toplama}

Bu çalışmada kullanılan ölçme aracı iki kısımdan oluşmaktadır. İlk kısımda katılımcıların demografik özelliklerini belirlemek aracıyla demografik değişkenler ile ilgili maddeler bulunmaktadır. Demografik değişkenlere ek olarak, bu kısımda katılımcıların ekonomik düzeylerinin belirlenmesi açısından ailesinin aylık kazancını ("0-2000","2001-4000" ve "4001 ve üstü") uygun olan seçeneği işaretlemeleri istenmiştir. Ayrıca "Anne/Baba Eğitim Düzeyi ve Yetiştiği Bölge ile ilgili sorulara ölçme aracında yer verilmiştir. İnternet kullanım alışkanlıklarını belirlemek amacıyla ise, İnternet Kullanım Sıklığı", "En Çok Kullanılan İnternet Erişim Aracı" ve "Öncelikli İnternet Kullanım Amacı" sorularına ölçme aracında yer verilmiştir.

Internet Tabanlı Epistemolojik İnançlar Ölçeği: İnternet Tabanlı Epistemolojik İnançlar Ölçeği (İTEIÖ) Braten, Brandmo ve Kammerer (2018) tarafindan geliştirilmiş 12 maddeden ve 3 faktörden (otoriteyle gerekçelendirme, birden fazla kaynak ile gerekçelendirme ve kişisel deneyimlerle gerekçelendirme) oluşan bir ölçektir. Ölçeğin orijinali Norveç'in kuzeyinde bulunan bir üniversitede öğrenim gören, yaşları 21 ile 33 arasında değişen öğretmen adayları üzerinde uygulanmıştır. Ters puanlanan maddenin bulunmadığı ölçek, uç değerler verilerek (Kesinlikle Katılmıyorum $=1$, Kesinlikle Katılıyorum =10) bireyin katılıp katılmama 
derecesinin sorulduğu bir 10'lu Likert ölçeğidir. Kișisel deneyimlerle gerekçelendirme altboyutu dört maddede oluşmaktadır ve bireyin internette eğitimle ilgili konuları değerlendirirken ne derece kişisel deneyimler ve mantığ 1 ile yorumlanması ile ilgili durumlara katılma derecesini ölçer. Otoriteyle gerekçelendirme alt-boyutu dört maddeden oluşmakta ve bireyin internette eğitim ile ilgili konuları değerlendirirken ne derecede kaynağın uzmanlığı ve yeterliği ile değerlendirmesi gerektiği ile ilgili fikirlerini ölçmektedir. Son olarak, çoklu kaynak ile gerekçelendirme alt boyutu dört maddeden oluşmakta ve bireyin internette eğitim ile ilgili konuları değerlendirirken ne derecede farklı kaynakların kullanılması gerektiği ile ilgili fikirlerini ölçmektedir. Braten ve arkadaşları ölçeğin Cronbach alfa değerlerini kişisel deneyimlerle gerekçelendirme için. 84, otoriteyle gerekçelendirme için. 92 ve çoklu kaynak ile gerekçelendirme için. 92 olarak rapor etmiştir. Ayrıca Braten ve arkadaşları yapılan doğrulayıcı faktör analizi sonucunda uyum indekslerini, $\mathrm{RMSEA}=.067, \mathrm{CFI}=.97$ ve $\chi 2 / \mathrm{df}=2,78$ olarak rapor etmiştir.

\section{İşlem ve veri analizi}

İnternet Tabanlı Epistemolojik İnançlar Ölçeğinin Türkçeye uyarlama çalışması öncelikle orijinal dilde ölçeğin geliştiricisi olan Braten, Brandmo ve Kammerer ile iletişime geçilerek ölçeğin uyarlanması için izin alınmasıyla başlamıştır. Gerekli izinler sağlandıktan sonra ölçeğin İngilizceden Türkçeye çeviri süreci alan uzmanları (iki İngiliz Dili Eğitimi, iki Türkçe Eğitimi, bir Rehberlik ve Psikolojik Danışmanlık ve bir Bilgisayar ve Öğretim Teknolojileri Eğitimi Bölümü) tarafindan yapılmıştır. Uzmanlardan gelen dönütler doğrultusunda her iki formun yeteri kadar birbirine benzediği görüşüne ulaşıldıktan (geri-çeviri yöntemi) sonra ölçeğin uygulamaya hazır son hali ortaya çıkarılmıştır. İTEİÖ'nün yapı geçerliliği çalışması doğrulayıcı faktör analizi (DFA) yöntemi kullanılarak yürütülmüştür. Ölçeğin güvenirlik düzeyi Cronbach alfa iç tutarlılık aracılığıyla incelenmiştir. İTEIÖ'nün uyarlama çalışmalarında kullanılan tüm istatistiksel analizler SPSS 22 ve AMOS 18.0 paket programlarıyla yapılmıştır. Öğretmen adaylarının internet tabanlı epistemolojik düzeyleri belirlendikten sonra kategorik değişkenlerin (cinsiyet, vb.) etkisini incelemek için t-test ve ANOVA, sıralama türü ölçülen değişkenlerle (Anne/baba eğitim düzeyi vb.) ilişkisini incelemek için ise Spearman Rho katsayısı hesaplanmıştır.

\section{Bulgular}

Öğretmen adaylarının internet kullanımı alışkanlıklarına Tablo 2'de yer verilmiştir. Buna göre çalışmaya katılan öğretmen adayları internet kullanım sıklıklarını genellikle günde 3-4 saat ve daha fazla olarak rapor etmiştir. İnternet kullanımı en az olan grup olan haftada 1-2 saat giren öğretmen adayları ise katılımcıların \%2,7 'lik bir kısmını oluşturmaktadır. Öğretmen adaylarının internete erişim için en çok kullandıkları araç ise akıllı telefondur $(\% 90,1)$. Öğretmen adayları interneti en fazla sosyal medyaya erişmek için kullanırken $(\% 62,9)$ en az ise haber ve dergi okumak için kullandıklarını görülmüştür $(\% 2,1)$.

Tablo 2.

Öğretmen Adaylarının Internet Kullanım Alışkanlıkları

\begin{tabular}{cll}
\hline İnternet Kullanım S1klığ & $\mathrm{f}$ & $\%$ \\
\hline Haftada 1-2 saat & 10 & 2,7 \\
Haftada 3-4 saat & 13 & 3,5 \\
Günde 1-2 saat & 81 & 21,6 \\
Günde 3-4 saat & 133 & 35,5 \\
Günde 4 saatten fazla & 138 & 36,8 \\
\hline En Çok Kullanılan İnternet Erişim Arac1 & & \\
\hline Akıllı Telefon & 338 & 90,1 \\
Dizüstü Bilgisayar (Laptop) & 30 & 8,0 \\
Masaüstü Bilgisayar & 7 & 1,9 \\
\hline
\end{tabular}




\begin{tabular}{lll}
\hline Öncelikli İnternet Kullanım Amacı & & \\
\hline Sosyal Medya (Facebook, İnstagram, Snapchat vb.) & 236 & 62,9 \\
Eğitim/Bilimsel Araştırma & 29 & 7,7 \\
İletişim (Görüntülü konuşma, E-posta vb.) & 60 & 16,0 \\
Oyun/Eğlence & 26 & 6,9 \\
Haber/Dergi Okuma & 8 & 2,1 \\
Kişisel (İnternet Bankacıllı̆̆ı, Çevrimiçi Alışveriș vb. ) & 16 & 4,3 \\
\hline
\end{tabular}

\section{Öğretmen adaylarının internet tabanlı epistemolojik inançları}

Doğrulayıcı faktör analizi çalışmalarında bazı uyum indekslerinin aranması gerekmektedir. Alan yazında en çok kullanılan uyum indeksi RMSEA ve CFI değerleridir. Bu değerlerden iyi uyum RMSEA değerinin 0.06 'dan az ve CFI değerinin 0.95 'ten yüksek olduğu durumdur. Yapılan analiz sonucu uyum indeks değerleri $\chi^{2}(51)=126, \mathrm{CFI}=0.98$ ve RMSEA $=0.053$ olarak bulunmuştur. Bu değerlerden ki-kare değerinin serbestlik derecesine (df) oranı iyi uyum düzeyi olan ikiden biraz yüksek kabul edilebilir düzey olan üçten ise düşüktür. Yalnız ki-kare değeri örneklemdeki kişi sayısından etkilendiği için tek başına yeterli değildir. Diğer uyum indekslerine bakıldığı zaman RMSEA ve CFI değerleri iyi uyum değerleri düzeyindedir. Ayrıca Şekil 1'de görüldüğü gibi yük değerleri 0.30 kesim değerinden yüksek ve faktörler arasında orta ile yüksek arasında korelasyon vardır. Bu değerler ölçeğin uyarlanan versiyonun geçerli olduğunu göstermektedir. Cronbach alfa $(\alpha)$ değerleri ise tüm alt-boyutlarda kabul edilebilir değer olan 0.70 'ten yüksektir (Tablo 3). Bu bulgular ölçeğin güvenilir ve geçerli olduğunu göstermektedir.

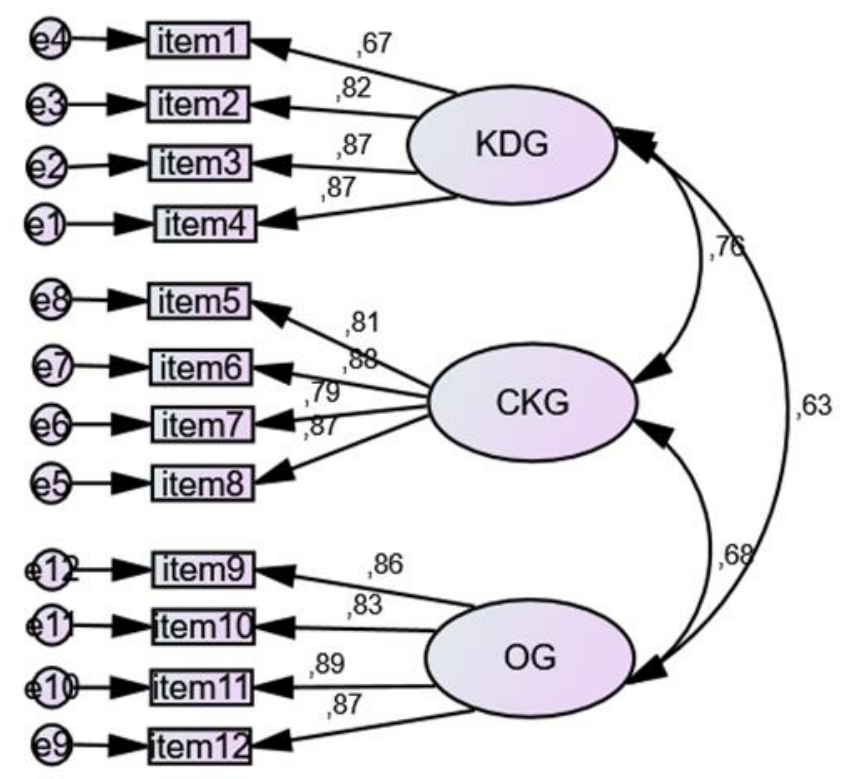

\section{Şekil 1.Faktör yük değerleri}

Öğretmen adaylarının internet tabanlı epistemolojik inançları her alt-boyut için ortalamaları Tablo 3'te verilmiştir. Elde edilen bulgulara göre, öğretmen adayları tüm epistemolojik inanç alt-boyutlarında yüksek düzeyde oldukları söylenebilir (1,00-4,00 arası düşük, 4,01-7,00 arası orta, 7,01-10,00 aras1 yüksek). Alt-boyutlar arasında öğretmen adayları internette eğitimle ile ilgili en çok kişisel deneyimlerini kullanarak bilgiyi yorumladıklarını beyan etmişlerdir. En az ise birden farklı kaynak kullanarak gerekçelendirme yaptıkları bulunmuştur. 
Tablo 3.

Öğretmen Adaylarının İnternet Tabanlı Epistemolojik İnançları

\begin{tabular}{llllll}
\hline & Ortalama & SS & Çarpıklık & Basıklık & $\alpha$ \\
\hline Kişisel deneyim ile gerekçelendirme & 8,03 & 1,66 &,- 95 &, 81 & .88 \\
Otoriteyle gerekçelendirme & 7,84 & 1,77 &,- 83 &, 49 & .90 \\
Çoklu kaynak ile gerekçelendirme & 7,49 & 1,87 &,- 74 &, 68 & .92 \\
\hline
\end{tabular}

Tablo 4'te öğretmen adaylarının internet tabanlı epistemolojik inançlarına demografik değişkenlerin etkisi değişimi incelenmiştir.T-tesi ve ANOVA testinden önce verilerin gerekli varsayımları, normal dağılım için Kolmogorov-Smirnov testi ve homogenlik içinse Levene testi ile kontrol edilmiştir. Yapılan bu testler veri dağılımlarının normal ve gruplar arası homojen olduğunu göstermiştir ( $\mathrm{p}>, 05)$. Yapılan t-testi ve ANOVA testlerinin sonuçlarına göre demografik değişkenlerden öğretmen adaylarının yetiştikleri bölgeye, annenin eğitim düzeyi ve ailelerinin toplam gelir düzeylerine göre internet tabanlı epistemolojik inançlarında istatiksel olarak anlamlı farklılık bulunmuştur. Buna göre kentsel bölgede yetişen öğretmen adaylarının internet tabanlı epistemolojik inançları kırsal bölgeden yetişen öğretmen adaylarından tüm altboyutlarda daha yüksektir (sirasiyla, $\mathrm{t}_{(373)}=-4,47 \mathrm{p}<.01$, Cohen's $\left.\mathrm{d}=.42, \mathrm{t}_{(373)}\right)=-3,89, \mathrm{p}<.01$, Cohen's $\mathrm{d}=.52$ ve $\mathrm{t}_{(373)}=-3,55, \mathrm{p}<.01$, Cohen's $\left.\mathrm{d}=, 42\right)$. ANOVA sonuçlarına göre annenin eğitim düzeyi öğretmen adaylarının kişisel deneyimlerle yorumlama fikirlerini etkilediğini görülmüştür $\left(\mathrm{F}_{(4,370)}=3,52, \mathrm{p}<.05, \eta^{2}=.03\right)$. Gruplardaki kişi sayısı farklı olduğu için yapılan Hochberg's GT2 post-hoc testi istatiksel anlamlı farkın anneleri üniversite mezunu ile ortaöğretim ve ilköğretim mezunu olanlar arasında üniversite mezunu olanlar lehine olduğunu göstermiştir $(\mathrm{p}<.05)$. Ailelerinin toplam gelir düzeyine bakıldığında sadece kişisel deneyimlerle gerekçelendirme alt-boyutunda anlamlı farklılık bulunmuştur $\left(\mathrm{F}_{(2,372)}=3,71, \mathrm{p}<.05, \eta 2=.02\right)$. Yapılan Hochberg's GT2 post-hoc t-testi sonucunda ise aylık toplam geliri 4000 TL ve üstü olan öğretmen adaylarının aylık toplam geliri 0-2000 TL arasında olanlardan kişisel deneyimlerle gerekçelendirme puanının istatistiksel olarak daha yüksek olduğu bulunmuştur ( $\mathrm{p}<$ $.05)$.

Tablo 4.

İnternet Tabanlı Epistemolojik Inançlara Demografik Değişkenlerin Etkisi

\begin{tabular}{llll}
\hline Cinsiyet & KDG & OG & ÇKG \\
\hline Kadın & 7,95 & 7,51 & 7,61 \\
Erkek & 8,07 & 7,47 & 7,95 \\
t-testi &,- 68 &, 212 & $-1,71$ \\
\hline Bölüm & & & \\
\hline Sinıf Öğretmenliği & 7,97 & 7,57 & 7,83 \\
Türkçe Öğretmenliği & 7,85 & 7,46 & 7,95 \\
Sosyal bilgiler öğretmenliğ̈i & 8,03 & 7,43 & 8,03 \\
Fen Bilgisi Öğretmenliği & 8,07 & 7,57 & 7,90 \\
Matematik Öğretmenliğ̈i & 8,53 & 8,15 & 8,43 \\
İngilizce Öğretmenliği & 7,34 & 7,08 & 6,94 \\
Okul Öncesi Öğretmenliği & 8,11 & 7,34 & 7,86 \\
Rehberlik ve Psikolojik Danışmanlık & 8,00 & 7,24 & 7,62 \\
F- değeri & 1,29 & 1,13 & 1,88 \\
\hline Yetiştiğiniz bölge & & & \\
\hline Kırsal kesim & 7,40 & 6,94 & 7,28 \\
Kentsel kesim & 8,28 & 7,69 & 8,06 \\
t-testi & $-4,74 * *$ & $-3,89^{* *}$ & $-3,55^{* *}$ \\
\hline Gelir düzeyi & & & \\
\hline 0-2000 TL & 7,78 & 7,34 & 7,63 \\
2001-4000 TL & 8,09 & 7,58 & 7,99
\end{tabular}




\begin{tabular}{llcc}
4001 TL- üstü & 8,40 & 7,58 & 7,97 \\
F-değeri & $3,71 * *$ & 1,81 &, 73 \\
\hline Anne eğitim düzeyi & & & \\
\hline İlköğretim & 7,87 & 7,79 & 7,35 \\
Ortaöğretim & 7,85 & 7,65 & 7,30 \\
Lise & 8,25 & 7,93 & 7,79 \\
Üniversite & 8,94 & 8,45 & 8,02 \\
Lisansüstü & 9,37 & 8,37 & 8,62 \\
F-değeri & $3,52^{*}$ & 1,70 & 1,19 \\
\hline Baba eğitim düzeyi & & \\
\hline İlköğretim & 7,92 & 7,42 & 7,87 \\
Ortaöğretim & 7,85 & 7,36 & 7,77 \\
Lise & 8,06 & 7,45 & 7,66 \\
Üniversite & 8,40 & 7,76 & 8,12 \\
Lisansüstü & 9,35 & 9,00 & 9,35 \\
F-değeri & 1,82 & 1,24 \\
\hline *p < .05, **p < .01, KDG: Kişisel deneyimle gerekçelendirme, OG: & Otoriteyle \\
gerekçelendirme ÇKG: Çoklu kaynak ile gerekçelendirme & \\
\hline
\end{tabular}

Öğretmen adaylarının internet tabanlı epistemolojik inançlarına internet kullanım alışkanlıklarının etkisini görmek için gruplar arası karşılaştırma yapılmış ve analiz sonuçları Tablo 5'de sunulmuştur. ANOVA sonuçlarına göre internet kullanım alışkanlıklarına göre öğretmen adaylarının internet tabanlı epistemolojik inançlarında farklılıklar olduğu görülmektedir. Diğer bir ifadeyle, internet tabanlı epistemolojik inançları kullanılan internet erişim aracına (kişisel deneyimle gerekçelendirme için $\left(\mathrm{F}_{(2,372)}=3,31, \mathrm{p}<.05, \eta 2=.02\right)$ ve otoriteyle gerekçelendirme $\left(\mathrm{F}_{(2,372)}=3,58, \mathrm{p}<.05, \eta 2=.02\right)$, internet kullanım siklığına (kişisel deneyimle gerekçelendirme için $\left(\mathrm{F}_{(4,370)}=4,33, \mathrm{p}<.05, \eta 2=.03\right)$ ve öncelikli internet kullanım amacı (kişisel deneyimle gerekçelendirme için $\left(\mathrm{F}_{(5,369)}=2,60, \mathrm{p}<.05, \eta 2=.01\right)$, otoriteyle gerekçelendirme için $\left(\mathrm{F}_{(5,369)}=2,61, \mathrm{p}<.05, \eta 2=.01\right)$, ve çoklu kaynak ile gerekçelendirme için $\left(\mathrm{F}_{(5,369)}=4,19, \mathrm{p}<.01, \eta 2=.03\right)$ göre farklılaşmaktadır. Yapılan Hochberg's GT2 post-hoc ttestleri sonucunda akıllı telefon ile erişenler ile dizüstü bilgisayar ile erişenler arasında, dizüstü bilgisayarlar erişenler lehine, otorite ile $(\mathrm{p}<.05)$ ve kişisel deneyimler ile gerekçelendirme $(\mathrm{p}<$ ,05) arasında istatiksel olarak anlamlı farklılık olduğunu göstermektedir. Aynı şekilde internete günde 1-2 saat kullananlar diğer gruplara göre en yüksek kişisel deneyimlerle gerekçelendirme epistemolojik inancına sahiptir. En düşük ortalama ise haftada 1-2 saat kullanım sıklığına sahip öğretmen adaylarıdır. Kullanım amacı gruplarına bakıldığında interneti eğitim/bilimsel araştırma için kullananlar diğer amaçlar için kullananlardan tüm epistemolojik alt-boyutlarında daha yüksek ortalama puana sahiptir. En düşük ortalama ise tüm alt-boyutlarda sosyal medya amacıyla interneti kullananlar grubunda gözlenmiştir.

Tablo 5.

İnternet Kullanım Alışkanlıklarına Göre ANOVA Sonuçları

\begin{tabular}{llll}
\hline & KDG & OG & ÇKG \\
\hline En Çok Kullanılan İnternet Erişim Aracı & & & \\
\hline Akıllı Telefon & 7,97 & 7,40 & 7,79 \\
Dizüstü Bilgisayar (Laptop) & 8,65 & 8,30 & 8,29 \\
Masaüstü Bilgisayar & 8,14 & 8,03 & 8,10 \\
F-değeri & $3,31^{* *}$ & $3,58^{* *}$ & 1,14 \\
\hline İnternet Kullanım Sıklığı & & & \\
\hline Haftada 1-2 saat & 6,52 & 7,75 & 7,42 \\
Haftada 3-4 saat & 6,96 & 6,71 & 7,13 \\
Günde 1-2 saat & 8,27 & 7,51 & 7,92
\end{tabular}




\begin{tabular}{llll} 
Günde 3-4 saat & 7,95 & 7,60 & 7,87 \\
Günde 4 saatten fazla & 8,17 & 7,40 & 7,86 \\
F-değeri & $4,33^{*}$ & 71 &, 82 \\
\hline Öncelikli İnternet Kullanım Amac1 & & & \\
\hline Sosyal Medya (Facebook, İnstagram, Snapchat vb.) & 7,79 & 7,21 & 7,64 \\
Eğitim/Bilimsel Araştırma & 8,68 & 8,67 & 8,75 \\
İletişim (Görüntülü konuşma, E-posta vb.) & 7,99 & 7,63 & 8,05 \\
Oyun/Eğlence & 8,67 & 8,01 & 8,19 \\
Haber/Dergi Okuma & 7,81 & 7,53 & 7,83 \\
Kişisel (İnternet Bankacılığı, Çevrimiçi Alışveriş vb. ) & 8,14 & 7,93 & 7,93 \\
F-değeri & $2,60 *$ & $2,61 *$ & $4,19 * *$ \\
\hline$*$ p <.05 ** p <.01 & & &
\end{tabular}

\section{Öğretmen adaylarının epistemolojik inançlar ile değișkenlerin ilișkisinin incelenmesi}

Tablo 6'da öğretmen adaylarının internet tabanlı epistemolojik inançların anne, baba eğitim düzeyi, gelir düzeyi ve internet kullanım sıklığı arasındaki ilişkiye ilişkin bulgular yer verilmiştir. Elde edilen bulgular internet tabanlı epistemolojik inançlar ile gelir düzeyi, anne eğitim düzeyi ve internet kullanım sıklığı ile ilişkili olduğunu göstermektedir. Diğer bir ifadeyle internet tabanlı epistemolojik inançlar boyutlarından sadece kişisel deneyimlerle gerekçelendirme alt-boyutu bu değişkenlerle istatistiksel olarak ilişkili bulunmuştur. $\mathrm{Bu}$ bulgulara göre öğretmen adaylarının kişisel deneyimlerle gerekçelendirme inançları, gelir düzeyi, anne eğitim düzeyi ve internet kullanım sıklığı ile pozitif ilişkilidir. Yani, gelir düzeyi, anne eğitim düzeyi ve internet kullanım sıklığı arttıkça kişisel deneyimlerle gerekçelendirme artmaktadır. Ayrıca internet kullanım sıklığı gelir düzeyi, anne ve baba eğitim düzeyi ile pozitif ilişkilidir. Yani öğretmen adaylarının gelir düzeyi, anne ve babalarının eğitim düzeyi arttıkça internet kullanım sıklığı artmaktadır. Anne ve baba eğitim düzeyleri de pozitif olarak birbiriyle ilişkilidir.

Tablo 6.

Değişkenler Arasında Spearman Rho Katsayıları

\begin{tabular}{llllllll}
\hline \multicolumn{1}{c}{} & 1 & 2 & 3 & 4 & 5 & 6 \\
\hline 1 & KDG & 1.00 & & & & & \\
2 & ÇKG & $\mathbf{, 6 7}^{* *}$ & 1.00 & & & & \\
3 & OG & $\mathbf{, 5 7}^{* *}$ &, $\mathbf{6 1}$ & 1.00 & & & \\
4 & Gelir düzeyi & $\mathbf{, 1 3}^{* *}$ &, 09 &, 06 & 1.00 & & \\
5 & Anne eğitim düzeyi &, $\mathbf{1 6}$ &, 05 &, 10 & $\mathbf{, 3 1}^{* *}$ & 1.00 & \\
6 & Baba eğitim düzeyi &, 08 &, 01 &, 04 & $\mathbf{, 3 1}^{* *}$ & $\mathbf{, 6 3}^{* *}$ & 1.00 \\
7 & İnternet kullanım siklı̆̆ &, $\mathbf{1 2 *}$ &, 03 &,- 03 & $\mathbf{, 1 0}^{*}$ & $\mathbf{, 1 3}^{*}$ &, 08 \\
\hline$* \mathrm{p}<.05 * * \mathrm{p}<.01$ & & & & & & \\
\hline
\end{tabular}

Tartışma,Sonuç ve Öneriler

Araştırma sonuçları şu şekildedir: Yapılan analiz sonucu ölçeğin uyum indeks değerleri $\chi^{2}(51)=$ $126, \mathrm{CFI}=0.98$ ve RMSEA $=0.053$ olarak bulunmuştur. Bu değerlerden ki-kare değerinin serbestlik derecesine (df) oranı iyi uyum düzeyi olan ikiden biraz yüksek kabul edilebilir düzey olan üçten ise düşüktür. Ayrıca yük değerleri 0.30 kesim değerinden yüksek ve faktörler arasında orta ile yüksek arasında korelasyon vardır. Bu değerler ölçeğin uyarlanan versiyonun geçerli olduğunu göstermektedir. Cronbach alfa $(\alpha)$ değerleri ise tüm alt-boyutlarda kabul 
edilebilir değer olan 0.70 'ten yüksektir. Bu bulgular ölçeğin güvenilir ve geçerli olduğunu göstermektedir.

Diğer taraftan öğretmen adaylarının ortalamalarının tüm internet tabanlı epistemolojik inanç alt-boyutlarında (KDG, OG ve ÇKG) yüksek düzeyde oldukları söylenebilir. Alt-boyutlar arasında öğretmen adayları internette eğitimle ile ilgili en çok kişisel deneyimlerini kullanarak bilgiyi yorumladıklarını rapor etmişlerdir. En az ise birden farklı kaynak kullanarak gerekçelendirme yaptıkları görülmüştür. Buradan hareketle öğretmen adaylarının internet tabanlı epistemolojik inançlarının yüksek düzeyde olduğu ve daha çok kişisel bilgilerini kullanarak veya otoriteyi mutlak bilginin kaynağı görerek ve bilgilerine güvenerek bilgiyi yorumladıkları sonucuna varılabilir. Benzer bulguya alan yazında farklı çalışmalarda da rastlanmaktadır. Örneğin, Acun, Yücel ve Demirhan (2018) üniversite öğrencilerinin bilginin kaynağı olarak en çok tecrübe ve otoriteyi kabul ettiklerini ifade etmiştir. Öğretmen adaylarının çoklu kaynak ile gerekçelendirme inançlarının diğer iki boyuta göre en az düzeyde olması bilginin nispeten sabit ve değişmez olduğu inancına sahip oldukları ve bilgiyi farklı kaynaklarla sorgulamadan kabul etme eğiliminde oldukları ve sofistike bir epistemolojik inanç geliştirmedikleri şekilde yorumlanabilir. Diğer bir ifadeyle, bilginin basit, kesin ve kendi muhakeme ve gözlemleri neticesinde oluşturulduğuna inanma eğiliminde oldukları söylenebilir.

Öğretmen adaylarının demografik değişkenlere göre internet tabanlı epistemolojik inançları ile internet kullanım alışkanlıklarına bakıldığında, yetiştikleri bölgeye, annenin eğitim düzeyi ve ailelerinin toplam gelir düzeylerine göre internet tabanlı epistemolojik inançlarında istatistiksel olarak anlamlı farklılık bulunmuştur. Buna göre, kentsel bölgede yetişen öğretmen adaylarının internet tabanlı epistemolojik inançları kırsal bölgeden yetişen öğretmen adaylarından tüm alt-boyutlarda daha yüksektir. Bu durum kentsel bölgede yetişen öğretmen adaylarının kendilerine sunulan internet tabanlı bilgileri olduğu gibi kabul etmeyip eleştirel bir şekilde ele almak istedikleri şeklinde anlaşılabilir. Ayrıca, annenin eğitim düzeyi öğretmen adaylarının kişisel deneyimlerle yorumlama fikirlerini etkilediğini görülmüştür. Ailelerinin toplam gelir düzeyine bakıldığında geliri $4000 \mathrm{TL}$ ve üstü olan öğretmen adaylarının kişisel deneyimlerle gerekçelendirme puanının istatistiksel olarak daha yüksek olduğu görülmüştür. $\mathrm{Bu}$ bağlamda ailenin özellikle annenin eğitim düzeyinin artmasıyla birlikte gelir düzeyi de artarak, öğretmen adaylarının internet ortamında bilgi arama ve yorumlama süreçlerinde farklı kaynakların karşılaştırılması, internet ortamında ulaşılan bilgilerin niteliğine ilişkin farkındalığın geliştiği söylenebilir. Diğer taraftan, sosyo-ekonomik seviyesi düşük öğretmen adaylarının geleneksel bilgiye daha fazla önem verdikleri sonucuna varılabilir. Benzer bulgulara alan yazında farklı çalışmalar da rastlanmaktadır (Acun ve diğerleri 2018; Alkın-Şahin, Tunca ve Ulubey, 2013; Çelen ve Seferoğlu, 2016; Efilti ve Çoklar, 2016; Üztemur ve Dinç, 2018). Bununla birlikte internete akıllı telefon ile erişenler ile dizüstü bilgisayar ile erişenler arasında, dizüstü bilgisayarlar erişenler lehine, otorite ile ve kişisel deneyimler ile gerekçelendirme arasında istatistiksel olarak anlamlı farklılık olduğunu göstermektedir. Yine ailenin gelir düzeyinin artmasıyla öğretmen adaylarının dizüstü bilgisayar sahibi olmalarının daha kolay olduğu ve gelir düzeyinin artmasıyla birlikte internet tabanlı bilgiyi daha sofistike değerlendirme farkındalığı oluştuğu (Ata ve Yıldırım, 2016) ve akıllı telefonlarını bilgi arama ve ulaşma yerine daha çok sosyal medya erişim kaynaklı kullandıkları şeklinde (Çelikkaleli, Ata ve Avc1, 2018) yorumlanabilir. Aynı şekilde internete günde 1-2 saat kullananlar diğer gruplara göre en yüksek kişisel deneyimlerle gerekçelendirme epistemolojik inancına sahiptir. Günde 3-4 saat internet kullanım sıklığı olanların daha çok sosyal medyada vakit geçirdikleri göz önünde bulundurulduğunda, öğretmen adaylarının sosyal medyayı bir bilgi kaynağı olarak ele almadıkları ve günde 1-2 saat internet kullanım sıklığı olanların interneti daha çok bir amaca yönelik kullandıkları şeklinde yorumlanabilir. Yine, kullanım amacı gruplarına bakıldığında interneti eğitim/bilimsel araştırma için kullananlar diğer amaçlar için kullananlardan tüm epistemolojik alt-boyutlarında daha yüksek ortalama puana sahiptir ve internet tabanlı bilginin kesin ve değişmez olduğuna inanma eğilimlerinin daha düşük olduğu söylenebilir. En düşük ortalama ise tüm alt-boyutlarda sosyal medya amaciyla interneti kullananlar grubunda gözlenmiştir. Elde edilen bu bulgular, internet tabanlı epistemolojik inançlar ile gelir düzeyi, 
anne eğitim düzeyi ve internet kullanım sıklığı ile ilișkili olduğunu göstermektedir. Bütün bu sonuçlar birlikte değerlendirildiğinde öğretmen adaylarının internet tabanlı epistemolojik inanç düzeyleri aile gelir durumu, anne eğitim düzeyi ve internet kullanım sıklığına göre değişim gösterdiği söylenebilir. Ancak farklı birçok etkenin de bu değişime etki etmiş olabileceği göz önünde bulundurulmalıdır.

Bilgi ve iletişim çağı olan 21 nci yüzyılda bireylerin internet tabanlı epistemik temellendirme konusundaki inançlarının eleştirel düşünme becerilerinde önemli bir rol oynayabileceği aşikârdır. Bu nedenle özellikle bireylerin yetişmesinde önemli rol oynayacak olan öğretmen adaylarının bu tür inançlarını belirlemek ve gerekli görüldüğünde bunları öğretim müdaheleleri yoluyla geliştirmeye çalışmak oldukça önemlidir. Bilginin kaynağını değerlendirmeyi hedef alan bu türbir önlem, bireylerin internet tabanlı inançlarını farkı kaynaklar ile temellendirmeye yöneltebilir. İnternet tabanlı epistemik inançlanı hedef alan bu tür müdaheleler internette akademik konularla ilgili okumalar yaparken özellikle birçok kaynaktan temellendirme inançlarını geliştirmede birelerin motivasyonlarını ve etkileşimlerini etkileyebilir. Bununla birlikte bu konuda daha fazla deneysel çalışmalara ihtiyaç vardır. Ayrıca, yapılan araştırmanın bir sinırlılığı olarak, çalışma içerisinde çok fazla grup olması ve örneklem sayısının az olması nedeniyle ölçme değişmezliği (measurement invariance) incelenmeden gruplararası farka bakılmıştır. Bu nedenle gruplararası farkla ilgili bulgular yorumlanırken bu durum göz önünde bulundurulmalıdır. Uyarlanan ölçekle ilgili olarak gruplararası fark1 test etmek isteyen araştırmacılar yeterli örneklemden elde edilen verilerle ölçme değişmezliğini test ederek (ölçme aracının gruplararası benzer özellik göstedigini kontrol ettinden sonra) bu çalışmada incelenen bağımsız değişkenlerin (cinsiyet, internet kullanımı vb.) internet tabanlı epistemolojik inançlara etkisini incelemeri önerilir.

\section{Kaynaklar}

Acun, İ., Yücel, C. ve Demirhan, G. (2018). Üniversite öğrencilerinin bilgi kaynakları. Journal of History Culture and Art Research, 7(1), 595-608.

Alkın-Şahin, S., Tunca, N. ve Ulubey, Ö. (2013). The relationship between preservice teachers' educational beliefs and critical thinking tendencies, European Conference on Curriculum Studies. Future Directions: Uncertainty and Possibility. University of Minho. 18-19 Ekim 2013, Portugal-Braga.

Alpaslan, M. M. (2017). Examining the relationship between personal epistemology and selfregulation among Turkish elementary school students. Journal of Educational Research, 110(4), 405-414.

Alpaslan, M. M. ve Ulubey, O. (2016). Öz-yeterlik ile epistemolojik inançlar ilişkisinin cinsiyet açısından incelenmesi. Ö. Demirel, M. Demirel, E. Yağcı ve N. Yazçayır (Yay. haz.) 4. Uluslararası Ĕgitim Programları ve Öğretim Kongresi Tam Metin Kitabı içinde (ss. 1118). Ankara: Pegem.

Alpaslan, M. M., Yalvac, B. ve Loving, C. C. (2017). High school physics students' personal epistemologies and school science practice. Science ve Education, 26, 841-865.

Alpaslan, M. M., Yalvac, B. ve Willson, V. (2017). A meta analytical review of the relationship between personal epistemology and self-regulated learning. Turkish Journal of Education, 6(2), 48-67.

Ata, R. ve Yıldırım, K. (2016). Öğretmen adaylarının medya okuryazarlığı dersi kapsamında internet ve sosyal medya kullanımları. Journal of Kirsehir Education Faculty, 17(2), 581-602.

Bråten, I., Brandmo, C. ve Kammerer, Y. (2018). A validation study of the internet-specific epistemic justification inventory with Norwegian preservice teachers. Journal of Educational Computing Research, 57(4), 877-900.

Chiu, Y. L., Liang, J. C. ve Tsai, C. C. (2016). Exploring the roles of education and Internet search experience in students' Internet-specific epistemic beliefs. Computers in Human Behavior, 62, 286-291. 
Cheng, K. H., Liang, J. C. ve Tsai, C. C. (2013). The role of Internet-specific epistemic beliefs and self-regulation in high school students' online academic help seeking: A structural equation modeling analysis. Journal of Educational Computing Research, 48(4), 469489.

Çelen, F. K. ve Seferoğlu, S. S. (2016). İnternet ortaminda öğrencilerin bilgi arama biçimleri: Stratejiler, tarzlar, tutumlar, gözlemler ve sorunlarla ilgili bir değerlendirme. Ö. Demirel ve S. Dinçer (ed.) içinde Eğitim bilimlerinde yenilik ve nitelik arayıı̧ı (2. Baskı) (69. Bölüm, 1147-1160). Pegem Akademi Yayıncılık, Ankara.

Çelikkaleli, Ö., Ata, R. ve Avc1, R. (2018). Orta ergenlik döneminde problemli internet kullanımının demografik değişkenler açısından incelenmesi. Journal of Computer and Education Research, 6(12), 123-141.

Çevik, Y. D. (2015). Predicting college students' online information searching strategies based on epistemological, motivational, decision-related, and demographic variables. Computers ve Education, 90, 54-63.

Efilti, E. ve Çoklar, A. N. (2016). The analysis of the relationship between epistemological beliefs and TPACK education competence among pre-service teachers. Journal of Human Sciences, 13(2), 2960-2971.

Go, E., You, K. H., Jung, E. ve Shim, H. (2016). Why do we use different types of websites and assign them different levels of credibility? Structural relations among users' motives, types of websites, information credibility, and trust in the press. Computers in Human Behavior, 54, 231-239.

Greene, J. A., Azevedo, R. ve Torney-Purta, J. (2008). Modeling epistemic and ontological cognition: philosophical perspectives and methodological directions. Educational Psychologist, 43(3), 142-160.

Greene, J. A., Yu, S. ve Copeland, D. Z. (2014). Measuring critical components of digital literacy and their relationships with learning. Computers ve Education, 76, 55-69.

Hajli, N. (2018). Ethical environment in the online communities by information credibility: a social media perspective. Journal of Business Ethics, 149(4), 799-810.

Hammer, D. ve Elby, A. (2002). On the form of personal epistemology. B. K. Hofer ve P. R. Pintrich (Yay. haz.), Personal epistemology: The psychology of beliefs about knowledge and knowing içinde (ss. 169-190). Mahwah, NJ: Erlbaum.

Hofer, B. K. (2016). Epistemic cognition as a psychological construct: Advancements and challenges. J. A. Greene, W. A. Sandoval, ve I. Bråten (Yay. haz.), Handbook of epistemic cognition içinde (ss. 19-38). New York, NY: Routledge

Hofer, B. K. ve Pintrich, P. R. (1997). The development of epistemological theories: beliefs about knowledge and knowing and their relation to learning. Review of Educational Research, 67, 88-140.

IBM Corp. Released (2012). IBM SPSS Statistics for Windows, Version 21.0. Armonk, NY: IBM Corp.

King, P. M. ve Kitchener, K. S. (2002). The reflective judgment model: Twenty years of research on epistemic cognition. B. K. Hofer ve P. R. Pintrich (Yay. haz.), Personal epistemology: The psychology of beliefs about knowledge and knowing içinde (s. 3761). Mahwah, NJ: Erlbaum.

Mason, L., Boldrin, A. ve Ariasi, N. (2010). Searching the Web to learn about a controversial topic: are students epistemically active? Instructional Science, 36(6).

Mason, L., Ariasi, N. ve Boldrin, A. (2011). Epistemic beliefs in action: spontaneous reflections about knowledge and knowing during online information searching and their influences on learning. Learning and Instruction, 21, 137-151.

Muis, K. R. (2007). The role of epistemic beliefs in self-regulated learning. Educational Psychologist, 42(3), 173-190.

Pew Research Center (2010). Online Activitieshttp://www.pewinternet.org/2010/12/16/onlineactivities/ (27.09.18 tarihinde erişildi) 
Perry, W. G., Jr. (1970). Forms of ethical and intellectual development in the college years: A scheme. New York: Holt, Rinehart and Winston.

Schommer, M. (1990). Effect of beliefs about the nature of knowledge on comprehension. Journal of Educational Psychology, 82, 498-504.

Strømsø, H. I. ve Bråten, I. (2010). The role of personal epistemology in the self-regulation of internet-based learning. Metacognition ve Learning, 5, 91-111.

Sinatra, G. M., Kienhues, D. ve Hofer, B. K. (2014). Addressing challenges to public understanding of science: Epistemic cognition, motivated reasoning, and conceptual change, Educational Psychologist, 49(2), 123-138.

Şenler, B. ve İrven, Ö. (2016). Primary pre-service teachers' epistemological beliefs and pseudoscientific beliefs. Mersin University Journal of the Faculty of Education, 12(2), 659-671.

Türkiye İstatistik Kurumu (2018) Hanehalkı bilişsim teknolojileri kullanım araştırması. Erişim adresi. http://tuik.gov.tr/HbPrint.do?id=27819

Trevors, G. J., Muis, K. R., Pekrun, R., Sinatra, G. M. ve Muijselaar, M. M. L. (2017). Exploring the relations between epistemic beliefs, emotions, and learning from texts. Contemporary Educational Psychology, 48, 116-132.

Üztemur, S. ve Dinç, E. (2018). Ortaokul öğrencilerinin epistemolojik inançlarının keşfedilmesinde öğrenci merkezli bir yaklaşım: Çiz-yaz-anlat tekniği. Journal of History Culture and Art Research, 7(3), 566-592.

You, K. H., Lee, S. A., Lee, J. K. ve Kang, H. (2013). Why read online news? The structural relationships among motivations, behaviors, and consumption in South Korea. Information, Communication ve Society, 16(10), 1574-1595.

Westerman, D., Spence, P. R. ve Van der Heide, B. (2014). Social media as information source: Recency of updates and credibility of information. Journal of Computer-Mediated Communication, 19(2), 171-183.

\section{Extended Abstract}

\section{Introduction}

The Internet plays an important role on information search and provides easy and quick access to many different sources of information. For this reason, the internet has become a source of information and the main channel for further communication across the world. Yuo et al. (2013) state that motivating factors in the use of the internet are information search, information tracking, entertainment and social benefit. In particular, the three most common online activities are using search engines to find information, social networking sites (eg, Facebook and Twitter) and news reading (Pew Research Center, 2010). These findings provide a basis for understanding and predicting the actual behavior of individuals regarding the use of online environments (Go et al., 2016). According to Turkey Statistical Institute (2018), the percentage of individuals using the Internet in Turkey has risen to $72.9 \%$. In addition, according to the results of household information technology usage research, $83.8 \%$ of households have access to internet from home. That is, eight out of ten households have internet access. However, online information can vary considerably in terms of quality and accuracy, since information sharing and spreading is free and free of charge on the Internet most of the time.

On the other hand, epistemological belief refers to ideas of an individual about the nature of knowledge and recognition. In the literature, different terms related to epistemological belief such as epistemological theories, personal epistemology and epistemic cognition have been used (Hofer, 2016). The first studies on epistemological beliefs were conducted by Perry (1970) with university students. Perry (1970) investigated how university students know their ideas about their cognition, what is the role of thinking and logical deductions in knowing and suggested the first model of epistemological beliefs. According to Perry, epistemological development consists of nine successive stages and four categories. In the first stage, dualistic 
stage, the individual identifies the information as true or false, while the individual considers himself as the source of knowledge in the last stage, relative being determined.

The importance of epistemic beliefs in online learning of students in the context of internet based learning has been examined and studies have shown that personal epistemic beliefs are effective in online information search (Mason et al., 2010b). In particular, it was observed that students tend to have epistemic beliefs about the uncertainty of internet-based information as their educational levels increase and they approach skeptical to the internet as a good source of accurate information and they tend to confirm and evaluate internet-based information with other sources (Chiu et al., 2016). In another study, Greene, Yu and Copeland (2014) examine the relation between students' learning in the internet learning environment and epistemic cognition and self-regulated learning. The pretest and posttest analysis results show that the students' epistemic cognitions are related to note-taking and exploratory learning strategies. Similarly, it is seen that students who have more experience on internet search develop their analytical and metacognitive strategies and scrutinise further accuracy and source of internet-based information (Çevik, 2015). Nevertheless, considering the internet as a source of information, it is stated that the positive effects of sophisticated epistemic beliefs on learning and the role of personal epistemic belief should be re-questioned (Cheng et al., 2013). It is considered that this study would contribute to the literature in this regard

\section{Method}

The study consists of two stages. The quantitative research model was formed in both stages. In the first stage, Internet-based Epistemological Beliefs Scale developed by Braten et al., (2018) was adapted to Turkish language. The second stage was carried out in relational research model and the relation between internet-based epistemological beliefs and internet usage of pre-service teachers was examined considering various variables. Internet-based Epistemological Beliefs Scale consists of twelve items in three dimensions as personal justification, justification by authority and justification by multiple sources. In this context, confirmatory factor analysis, internal consistency tests, and relational analysis techniques were performed based on data obtained from these individuals.

\section{Result and Discussion}

As a result of the analysis, the fit index values were $\chi^{2}(51)=126, \mathrm{CFI}=0.98$ and RMSEA $=$ 0.053. Of these values, the ratio of the chi-square value to the degree of freedom (df) is lower than two with a good fit, and lower than three of the acceptable levels. In addition, factor load values are higher than the cutoff value of .30 and there is a moderate and high correlation between factors. Cronbach alpha $(\alpha)$ values are higher than acceptable value of .70 in all subdimensions. These findings indicate that the adapted scale is reliable and valid.

On the other hand, it was observed that mean scores of pre-service teachers are at a high level in the all internet-based epistemological belief sub-dimensions. Among sub-dimensions, pre-service teachers reported that they interpret the educational/scientific information on the internet with their personal experiences at most. It is seen that they made justification using multiple sources at least.

When internet-based epistemological beliefs and internet usage habits of pre-service teachers were examined considering demographic variables, a statistically significant difference was observed in their epistemological beliefs according to their region, mother's educational level and families' total income level. According to this, the internet-based epistemological beliefs of pre-service teachers in the urban region are higher in all sub-dimensions than preservice teachers who are raised in rural areas. In addition, it was observed that the mother's level of education influenced the ideas of pre-service teachers to interpret the information with personal experiences. It was also observed that the reasoning with personal experiences score of the pre-service teachers with an income of $4000 \mathrm{TL}$ and above was statistically higher. Furthermore, there is a statistically significant difference between those accessing the internet via a smartphone and those accessing the internet via a laptop in favor of those who access the 
internet via laptops between reasoning with authority and personal experience scores. Similarly, thow who access the internet 1-2 hours per day have the highest reasoning with personal experience epistemological beliefs compared to other groups. Furthermore, those who access the internet for educational/scientific research had higher average scores in all epistemological sub-dimensions than those who use the internet for other purposes. When all these results are interpreted together, it can be said that pre-service teachers' internet-based epistemological belief levels change according to family income, mother education level and frequency of internet usage. 